Editorial

\title{
Extensor mechanism reconstruction in the setting of infected total knee arthroplasty
}

\author{
Lucy Cogswell $^{\bowtie}$, Rob McCulloch \\ Nuffield Orthopaedic Centre, Oxford University Hospitals NHS Foundation Trust, UK \\ $\triangle$ Corresponding author: Miss Lucy Cogswell, Department of Plastic \& Reconstructive Surgery, Oxford Radcliffe Hospitals NHS Foundation Trust, Headley \\ Way, Oxford, OX3 9DU, UK. Email: lucy.cogswell@ouh.nhs.uk \\ (C) The author(s). This is an open access article distributed under the terms of the Creative Commons Attribution License (https://creativecommons.org/licenses/by/4.0/). \\ See http://ivyspring.com/terms for full terms and conditions.
}

Received: 2020.04.03; Accepted: 2020.04.03; Published: 2020.06.12

Infection in a total knee arthroplasty (TKA) is a devastating but rare complication with an incidence of roughly one percent (1). A timely and accurate diagnosis of periprosthetic joint infection (PJI) thorough pre-operative planning and adherence to treatment principles, ideally within a multidisciplinary setting - are essential in successful management (2). The decision regarding whether the patient is appropriate for debridement, antibiotics and implant retention (DAIR), single stage or two stage revision is based on many factors including knowledge of the pathogen, component fixation, patient co-morbidities and the surrounding soft-tissue envelope (3). Success rates of a DAIR procedure vary between institutions from $31 \%$ to $100 \%$ when using eradication of infection as the outcome measure (3). Key to the success of any revision procedure for PJI is adequate soft tissue cover and where necessary plastic surgical techniques to facilitate this.

Bringing healthy soft tissue into the wound releases tension in the skin around the knee, helps to fill dead space, and adds well-vascularised tissue which is postulated to improve antibiotic delivery to the wound (4). As yet there is no definite evidence that a muscle flap is superior to a skin and fascia flap in the face of infection. The proximity of the gastrocnemius muscle, its convenient anatomy in terms of length and vascular pedicle, and its expendability make it a frequent choice for a flap in this region (5-9). The majority of infected TKAs needing flap cover can be closed with gastrocnemius muscle flaps. In our personal series of forty-six flaps for infected TKA, only two needed flaps other than gastrocnemius: one due to the size of the defect, the second because gastrocnemius had already been used in a previous procedure. Both had free latissimus dorsi reconstructions (unpublished data).

It is unusual for the extensor mechanism to be deficient after infection; in our practice this situation more commonly arises after tumour resection from the proximal tibia (4). However, similar reconstructive principles can be applied. Whilst a muscle-alone reconstruction has been described for the patellar tendon using only the fascia around a muscle flap to bridge the tendon gap $(10,11)$, a common issue with all reconstructive techniques for a failed extensor mechanism in the context of revision arthroplasty or sarcoma is an extensor lag $(12,13)$.

The utilisation of a robust tissue such as a tendon to integrate into the extensor remnant helps to minimise this problem $(12,13)$. Due to the extensive soft tissue releases associated with revision surgeries often requiring constrained hinged implants, stiffness is not frequently a significant impediment to patient function and outcome (14). Vascularised, autologous tissue is preferable over alloplastic implants in the presence of infection (15). Around the knee, two of the most commonly described vascularised autologous tissue reconstructions are the gastrocnemius muscle with attached Achilles tendon, and a tube of fascia created as part of an anterolateral thigh (ALT) flap. However, any other expendable tendon or dense fascia with a known vascular pedicle can be used. Around the ankle, multiple flaps have been described to reconstruct the Achilles tendon, including local tissue (4) fascia lata (15), adductor magnus tendon 
(16), groin flaps (17) parascapular flaps (18) as well as the ALT flap (19), and all of these techniques could equally be applied to the knee.

In our unit, we routinely use the gastrocnemius muscle flap for extensor mechanism reconstruction. If a two-stage procedure is planned, the muscle flap is ideally performed at the first stage. After wound debridement and lavage, approximately $25 \%$ of the Achilles tendon is harvested in continuity with the medial head of gastrocnemius, based on the proximal neurovascular pedicle. The tendon is sharply dissected from the distal part of the muscle, keeping the proximal portion of tendon attached to the muscle. This dissection allows a degree of freedom in arranging the tendon and muscle in the recipient bed. The fibrous tissue on the anterior and posterior surfaces of the muscle is scored in a 'mango-cutting' technique. This increases the effective surface area of muscle and makes it more supple to conform to the recipient bed. The flap is tunnelled subcutaneously to the defect. The proximal end of the tendon is sutured to the residual extensor remnant. The tendon is then fed through a transverse cut in the gastrocnemius muscle belly. Its distal end is sutured on (i) to the tibial periosteum in the region of the tibial tuberosity and (ii) to any residual patellar ligament if present. During this procedure the knee is in extension. In the context of a proximal tibial replacement where the tibial tuberosity has been sacrificed, the tendon is attached to the fascia around tibialis anterior. The native knee skin and the muscle flap are arranged to completely cover the Achilles tendon. The lateral head of gastrocnemius is also added to the construct when needed for soft tissue cover. Any exposed muscle is covered with split thickness skin graft.

Postoperatively, we keep the knee in extension for 3 months, and then begin gradual flexion under the supervision of a physiotherapist, using a hinged knee brace to incrementally increase the range and allow the patient to mobilise locked in extension to minimise the risk of extensor lag.

In addition to a thorough and careful debridement, three elements of surgical practice help to preserve the soft tissue envelope. Firstly, in the first part of a two-stage procedure, a cement spacer is used which reflects the real dimensions of the planned implant. This avoids the skin contraction which can result from leaving an 'underfilled' joint. Secondly, anterior knee wounds are not left open to drain which avoids skin retraction. Thirdly, if the knee does need to be opened more than once, care is taken with wound closure to avoid the scenario where sutures cut through the skin as it swells, leading to a frayed skin margin, or even complete skin necrosis along the suture line.
In our practice, we rarely need to use free flaps to replace lost skin in infected total knee arthroplasty, and therefore gastrocnemius-based flaps form the majority of extensor mechanism reconstructions. Equally, on the rare cases when we do encounter a larger skin defect, it is important that as surgeons working in the field of infected TKA, plastic surgeons have the flexibility to reconstruct all defects, as the case series of Osinga et al. (20) so beautifully illustrates.

\section{Competing Interests}

The authors have declared that no competing interest exists.

\section{References}

1. Kurtz SM, Lau EC, Son MS, Chang ET, Zimmerli W, Parvizi J. Are we winning or losing the battle with periprosthetic joint infection: trends in periprosthetic joint infection and mortality risk for the medicare population. The Journal of arthroplasty. 2018 Oct 1;33(10):3238-45.

2. Yan $\mathrm{CH}$, Arciola CR, Soriano A, Levin LS, Bauer TW, Parvizi J. Team approach: The management of infection after total knee replacement. JBJS reviews. 2018 Apr 1;6(4):e9.

3. Zaruta DA, Qiu B, Liu AY, Ricciardi BF. Indications and guidelines for debridement and implant retention for periprosthetic hip and knee infection. Current reviews in musculoskeletal medicine. 2018 Sep 1;11(3):347-56.

4. McCulloch R, Theologis T, Giele H, Cogswell L, Whitwell D, Gibbons M. Extensor mechanism reconstruction of the knee using a gastrocnemius flap. 2019. Presentation to British Orthopaedic Oncology Society.

5. Ger, R. The technique of muscle transposition in the operative treatment of traumatic and ulcerative lesions of the leg. J Trauma. 1971; II: 502.

6. Michael Pers, Sandor Medgyesi. Pedicle muscle flaps and their applications in the surgery of repair. Br J Plast Surg. 1973; 26: 313-321.

7. McHugh, M, Prendiville, J. B. Muscle flaps in the repair of skin defects over the exposed tibia. Br J Plast Surg. 1975; 28: 205.

8. Nabil I. Elsahy. Cover of the exposed knee joint by the lateral head of the gastrocnemius. Br J Plast Surg. 1978; 31: 136-137.

9. Arthur M. Morris. A gastrocnemius musculocutaneous flap. Br J Plast Surg. 1978; 31: 216-219.

10. N. Victor Babu, Samuel Chittaranjan, George Abraham, Suranjan Bhattacharjee, Hari Prem, Ravi J. Korula. Reconstruction of the quadriceps apparatus following open injuries to the knee joint using pedicled gastrocnemius musculotendinous unit as bridge graft. Br J Plast Surg. 1994; 47:190-193.

11. R. Hierner, P. Reynders-Frederix, J. Bellemans, J. Stuyck, W. Peeters. Free myocutaneous latissimus dorsi flap transfer in total knee arthroplasty. J Plast Reconstr Aesth Surg. 2008; 62: 1692-1700.

12. Titus V, Clayer M. Protecting a patellar ligament reconstruction after proximal tibial resection: a simplified approach. Clin Orthop Relat Res. 2008;466:1749-1754. doi: 10.1007/s11999-008-0239-y.

13. Jentzsch T, Erschbamer M, Seeli F, Fuchs B. Extensor Function After Medial Gastrocnemius Flap Reconstruction of the Proximal Tibia. Clin Orthop Relat Res. 2013 Jul; 471(7): 2333-2339.

14. Hermans K, Vandenneucker H, Truijen J, Oosterbosch J, Bellemans J. Hinged versus CCK revision arthroplasty for the stiff total knee. The Knee. 2019 Jan 1;26(1):222-7.

15. M. Neuwirth, H. Bürger, W. Palle, M. Rab. One-stage reconstruction of isolated and combined tendon defects with the vascularized adductor magnus tendon graft: Surgical technique and preliminary results. J Plast Reconstr Aesth Surg, 2016; 69:928-935.

16. Inoue, $\mathrm{T}$., Tanaka, I., Imai, K. et al. Reconstruction of Achilles tendon using vascularised fascia lata with free lateral thigh flap. Br J Plast Surg. 1990; 43: 728-731.

17. Wei, F.C., Chen, H.C., Chuang, C.C. et al. Reconstruction of Achilles tendon and calcaneus defects with skin-aponeurosis-bone composite free tissue from the groin region. Plast Reconstr Surg. 1988; 81: 579-589.

18. Sauerbier, M., Erdmann, D., Schepler, H. et al. The scapular/parascapular flap in reconstruction of distal lower extremity soft tissue defects over the Achilles tendon. Eur J Plast Surg. 1998; 21: 333-337 
19. Lee, J.W., Yu, J.C., Shieh, S.J. et al. Reconstruction of the Achilles tendon and overlying soft tissue using antero-lateral thigh free flap. Br J Plast Surg. 2000; 53: 574-577.

20. Osinga R, Eggimann MM, Lo SJ, Kühl R, Lunger A, Ochsner PE, Sendi P, Clauss M, Schaefer DJ. Orthoplastics in Periprosthetic Joint Infection of the Knee: Treatment Concept for Composite Soft-tissue Defect with Extensor Apparatus Deficiency. J Bone Jt Infect. 2020; 5(3): 160-171. doi:10.7150/jbji.47018. 